(139)

\title{
Antioxidant and Cytotoxic Activities of Passiflora suberosa L. Leaf Extracts
}

\author{
Bandara K.R.V. ${ }^{1}$, Padumadasa C. $^{2}$ and Peiris L.D.C. ${ }^{* *}$ \\ ${ }^{1}$ Department of Zoology, University of Sri Jayewardenepura, Sri Lanka \\ ${ }^{2}$ Deaprtment of Chemistry, University of Sri Jayewardenepura, Sri Lanka \\ *dinithi@sci.sjp.lk
}

\begin{abstract}
In the Ayruvedic herbal system in Sri Lanka, Passiflora suberosa is used to treat many diseases including diabetes. The present study was conducted to evaluate in vitro antioxidant potential and cytotoxic activities of methanol and water extracts, obtained from $P$. suberosa leaves. $P$. suberosa leaves were powdered and extracted with methanol and water to obtain the crude extracts. Antioxidant capacity of different concentrations of aqueous and methanol extracts were determined by their ability to scavenge free radical using 1-diphenyl-2-picryl-hydrazil (DPPH) and by antihaemolytic activity. Similar concentrations were further tested for cytotoxicity using brine shrimps cytotoxicity assay. IC50 values were calculated to evaluate both antioxidant properties and toxicity of plant extracts. According to DPPH assay, IC50 values of both aqueous and methanol leaf extracts were $74.33 \mu \mathrm{g} / \mathrm{ml}$ and $418.67 \mu \mathrm{g} / \mathrm{ml}$ respectively. The IC50 value of the aqueous extract of $P$. suberosa leaf was significantly less than that of the standard ascorbic acid, which was found to be $166.17 \mu \mathrm{g} / \mathrm{ml}$. Whereas IC50 values of antihaemolytic activity were $80.08 \mu \mathrm{g} / \mathrm{ml}$ and $610.25 \mu \mathrm{g} / \mathrm{ml}$ in aqueous and methanol leaf extracts respectively. Results from brine shrimp cytotoxicity assay, showed that IC50 values for aqueous and methanol extracts of $P$. suberosa leaves were $60.26 \mu \mathrm{g} / \mathrm{ml}$ and 309.02 $\mu \mathrm{g} / \mathrm{ml}$ respectively. The aqueous extract of $P$. suberosa leaves exhibited better antioxidant activity and cytotoxic activity than the methanol extract. Hence, present findings suggest that extracts of $P$. suberosa leaves possess applicable natural antioxidant and cytotoxic potential. Further, $P$. suberosa leaves possess better antioxidant activity than ascorbic acid, which is a well-established antioxidant. Hence, extracts from P. suberosa leaves can be considered as potential antioxidant and cytotoxic agents as well as imminent candidate for cancer therapy.
\end{abstract}

Keywords: Passiflora suberosa, Antioxidant, Cytotoxic, IC50 values

Proceedings of the International Forestry and Environment Symposium 2016, Department of Forestry and Environmental Science, University of Sri Jayewardenepura, Sri Lanka. 